E.L.U.A. 2, 1984, págs. 251-271

\title{
FOCALIZACIÓN Y ESTRUCTURA TEXTUAL: LA CAPILLA DE BRANDESO EN LA «SONATA DE OTOÑO»
}

\author{
JOSE MARIA POZUELO YVANCOS \\ (Universidad de Murcia) \\ A la memoria de \\ D. Mariano Baquero Goyanes
}

\section{Composición textual y niveles de análisis}

La bibliografía sobre los procedimientos discursivos como elementos estructuradores de la composición del texto narrativo es hoy muy extensa. Por vías a veces separadas el formalismo eslavo, la semiótica de Bajtin (1970) proyectada más recientemente sobre el importante libro de Uspenki (1973), la critica norteamericana que arranca de $H$. James en obras como las de Scholes-Kellogg (1966) o Friedmann (1967) y por último del neoformalismo francés a través sobre todo de Todorov (1969), G. Genette (1972). M. Bal (1977), por citar sólo textos representativos de actitudes teóricas diversas sobre un mismo punto, han proporcionado abundante material sobre la composición del discurso narrativo' y en concreto sobre el perspectivismo como elemento estructurador. En España ocupó en este terreno posición pionera, agudísima y propiamente orteguiana Baquero Goyanes en diferentes libros (vid. Baquero Goyanes 1963 y 1970) que A. Garcia Berrio valoró como avances teóricos coincidentes con los que luego conoceriamos a través de los formalistas (vid. A. Garcia Berrio 1973 y 1984). En otro lugar pude hacer una

1 Enviado a imprenta este estudio, he conocido el importante libro de F. Martínez Bonat: La estructura de la obra literaria. Barcelona, Ariel, $1983^{3}$. Sus agudas teorías sobre la enajenación mimética y su fundamentada distinción lógica entre "hablar del narrador" y «hablar de las figuras" son muy pertinentes para profundizar en algunas de las cuestiones aquí tratadas. 
sintesis de algunas de tales aportaciones que ahora sería inútil repetir (cf. J. M. Pozuelo, 1983: 137-140). Mi intención en este estudio es plantear, al hilo del análisis de un fragmento de la Sonata de Otoño de Valle-Inclán, dos cuestiones metodológicas de diferente alcance. La primera cuestión, de alcance mínimo, es llamar de nuevo la atención acerca de la enorme importancia de la estructura discursiva en el planteamiento de comentarios de texto en prosa, incluso si se trata de fragmentos y no de obras completas. Las numerosas, quizá en exceso, metodologías de comentario de textos al uso de nuestros universitarios conceden escasísima etención a los problemas discursivos.

La segunda cuestión de alcance más teórico, se refiere a la definición misma de la estructura discursiva en relación con los planos de análisis. La extendida práctica del análisis por niveles que vino a la crítica literaria por la vía de la retórica y confirmó luego el análisis lingüístico, ha llegado a plantear la posibilidad de entender la composición textual narrativa como un fenómeno analizable en diferentes niveles y planos. T. Todorov (1969) hablaba de aspecto, modo, voz y tiempo (en un evidente isomorfismo con la estructura lingüistico-verbal) y $G$. Genette (1972) incluye el aspecto o perspectiva como una parte de la modalidad. Por otra via teórica ha coincidido en el planteamiento de niveles B. Uspenki en su libro citado A Poetics of Composition. Uspenki habla alli de cuatro planos composicionales: el ideológico, el fraseológico, el espacio-temporal y el psicológico, si bien afirma que tales planos son productos de la descripción crítica y no propiedades objetivas de los textos; son, por tanto, «planos de análisis» (B. Uspenki, 1973: 6) y en el capitulo $V$ del libro puede hablar de la interrelación de planos o niveles de puntos de vista en una obra. También los neoformalistas franceses, tanto en su posición teórica como en sus análisis concretos, han hablado de la convergencia de todos los niveles en la unidad textual. El problema puede advenir, volviendo a Uspenki, en haber aislado, como un plano de análisis, el fraseológico. Cuando to hace, en el capítulo II de su libro, aparte de referirse a problemas de Denominación de personajes, viene a actualizar en el análisis de Guerra y Paz importantes logros teórico-metodológicos de la semiótica eslava sobre los tipos de discurso, concretamente la aportación de Voloshinov $\left(1976_{2}\right)$, para trazar por último la distinción entre discurso auctorial y discurso de los personajes con sus diferentes oscilaciones e intromisiones del uno en los otros y viceversa.

$\mathrm{Tal}$ proceder, presentado como metodológico, puede ocultar a mi juicio una evidencia que quiero destacar en el análisis del texto de Valle Inclán: cualquiera otro plano de análisis — también el ideológico-es inevitablemente fraseológico, penetra en la estructura misma de la len- 
gua del texto de modo que éste da cuenta siempre no sólo de la historia sino de la actividad de contarla o "discurso". Que ese discurso es inevitablemente un tejido polifónico, por utilizar terminologia bajtiniana, ha de ser una de las conclusiones teóricas de todo análisis. Y es así precisamente en la medida en que el nivel fraseológico no puede predicarse como un nivel del estudio en el mismo plano que los otros niveles, y por tanto aislable en la metodologia de análisis. Por el contrario el fraseológico es el lugar de encuentro de los otros niveles, el punto de convergencia que define el texto como objeto y por tanto no extrapolable a un nivel metatextual o metadiscursivo. La noción misma de «discurso verbal", que afecta a cualquier texto literario, implica que la perspectiva ideológica, la espacio-temporal y la psicológica son solamente posibles en el plano fraseológico, que, lejos de actuar como un nivel analítico más, adquiere la posición de punto de encuentro de los diferentes planos. Para evitar problemas terminológicos llamo Focalización al elemento fraseológico organizador de ese encuentro o convergencia de las estructuras espaciales, temporales, ideológicas, psicológicas etc.

\section{Focalización y texto: la capilla de los Brandeso en la Sonata de Otoño}

2.0. Las mínimas propuestas teóricas que acabo de resumir han de contrastarse con el análisis concreto de un texto que no ha sido elegido ad hoc como podrá deducirse de su aparentemente escasa riqueza perspectivística. Se trata de un texto con un solo narradorfocalizador y que carece de palabras de los personajes o discurso transpuesto (G. Genette, 1972: 191). Pero no siempre es interesante ejemplificar con textos elegidos ad hoc y parece en cambio más interesante poder decir que las conclusiones obtenidas se defenderian a fortiori en ese otro tipo de textos más complejos en cuanto a planos perspectivísticos. En el texto objeto de mi análisis - siendo mínimamente rico- veremos jugar al mismo tiempo muy diferentes planos prendidos a su estructura fraseológica.

\subsection{He aquí el texto que nos proponemos analizar:}

"La capilla era húmeda, tenebrosa, resonante. Sobre el retablo campeaba un escudo de dieciséis cuarteles, esmaltados de gules y de azur, de sable y de sinople, de oro y de plata. Era el escudo concedido por ejecutorias de los Reyes Católicos al Capitán Alonso Bendaña, fundador del Mayorazgo de Brandeso: ¡Aquel Capitán que en los Nobiliarios de Galicia tiene una leyenda bárbara! Cuentan que habiendo hecho 
prisionero en una cacería a su enemigo el Abad de Mos, le vistió con pieles de lobo y le soltó en el monte, donde el Abad murió atarazado por los perros. Candelaria, la niñera de Concha, que, como todos los criados antiguos, sabía historias y genealogías de la casa de sus señores, solía en otro tiempo referirnos la leyenda del Capitán Alonso Bendaña, como la refieren los viejos Nobiliarios que ya nadie lee. Además, Candelaria sabía que dos enanos negros se habian llevado al infierno el cuerpo del Capitán. ¡Era tradicional que en el linaje de Brandeso los hombres fuesen crueles y las mujeres piadosas!

Yo aún recuerdo aquel tiempo cuando había capellán en el Palacio y mi tía Agueda, siguiendo añeja e hidalga costumbre, oía misa acompañada por todas sus hijas, desde la tribuna señorial que estaba al lado del Evangelio. En la tribuna tenían un escaño de velludo carmesí con alto respaldar que coronaban dos escudos nobiliarios, pero solamente mi tía Agueda, por su edad y por sus achaques, gozaba el privilegio de sentarse. A la derecha del altar estaba enterrado el Capitán Alonso Bendaña con otros caballeros de su linaje: El sepulcro tenia la estatua orante de un guerrero. A la izquierda estaba enterrada Doña Beatriz de Montenegro, con otras damas de distinto abolengo: El sepulcro tenia la estatua orante de una religiosa en hábito blanco como las Comendadoras de Santiago. La lámpara del presbiterio alumbraba día y noche ante el retablo labrado como joyel de reyes: Los áureos racimos de la vid evangélica parecian ofrecerse cargados de fruto. El santo tutelar era aquel piadoso Rey Mago que ofreció mirra al Niño Dios: Su túnica de seda bordada de oro brillaba con el resplandor devoto de un milagro oriental. La luz de la lámpara, entre las cadenas de plata, tenía tímido aleteo de pájaro prisionero, como si se afanase por volar hacia el Santo.

Concha quiso que fuesen sus manos las que dejasen aquella tarde a los pies del Rey Mago los floreros cargados de rosas, como ofrenda de su alma devota. Después, acompañada de las niñas, se arrodilló ante el altar. Yo desde la tribuna solamente oía el murmullo de su voz, que guiaba moribunda las avemarías, pero cuando a las niñas les tocaba responder, oia todas las palabras rituales de la oración. Concha se levantó besando el rosario, cruzó el prebisterio santiguándose y llamó a sus hijas para rezar ante el sepulcro del guerrero, donde también estaba enterrado Don Miguel Bendaña. Aquel señor de Brandeso era abuelo de Concha. Hallábase moribundo cuando mi madre me llevó por primera vez al Palacio. Don Miguel Bendaña había sido un caballero déspota y hospitalario, fiel a la tradición hidalga y campesina de todo su linaje. Enhiesto como un lanzón, pasó por el mundo sin sentarse en el festín de los plebeyos. ¡Hermosa y noble locura! A los ochenta años, cuando murió, aún tenía el alma soberbia, gallarda y bien templada, 
como los gavilanes de una espada antigua. Estuvo cinco dias agonizando, sin querer confesarse. Mi madre aseguraba que no habia visto nada semejante. Aquel hidalgo era hereje. Una noche, poco después de su muerte, oi contar en voz baja que Don Miguel Bendaña había matado a un criado suyo. ¡Bien hacía Concha rezándole por el alma!

La tarde agonizaba y las oraciones resonaban en la silenciosa oscuridad de la capilla, hondas, tristes y augustas, como un eco de la Pasión. Yo me adormecía en la tribuna. Las niñas fueron a sentarse en las gradas del altar: Sus vestidos eran albos como el lino de los paños litúrgicos. Yo sólo distingui una sombra que rezaba bajo la lámpara del presbiterio: Era Concha. Sostenía entre sus manos un libro abierto y leía con la cabeza inclinada. De tarde en tarde el viento mecía la cortina de un alto ventanal: Yo entonces veía en el cielo ya oscuro, la faz de la luna, pálida y sobrenatural, como una diosa que tiene su altar en los bosques y en los lagos... Concha cerró el libro dando un suspiro, y de nuevo llamó a las niñas. Vi pasar sus sombras blancas a través del presbiterio y columbré que se arrodillaban a los lados de su madre. La luz de la lámpara temblaba con un débil resplandor sobre las manos de Concha, que volvían a sostener abierto el libro. En el silencio su voz leía piadosa y lenta. Las niñas escuchaban, y adiviné sus cabelleras sueltas sobre la albura del ropaje. Concha leía.»

(Valle Inclán, 1902: 74-76)

2.2. Situemos primeramente el texto en el conjunto de la Sonata de Otoño del que forma parte. Esta situación la dibujaré en dos trazos: primeramente su posición sintagmática o co-textual en el desarrollo lineal de la obra. Después aludiré a la relación del texto con el conjunto significativo de la Sonata.

2.2.1. La descripción de la escena de la capilla se encuentra casi al final de la obra. Si repasamos brevemente la historia narrada en la Sonata de Otoño vemos que se trata de un conjunto de evocaciones prendidas al hilo de una historia amorosa: las relaciones del Marqués de Bradomín con su prima Concha de Brandeso. Después de un tiempo de ausencia, el Marqués de Bradomín acude a la llamada de su prima, quien se halla moribunda. Durante algo más de tres dias, en un tiempo medido por el narrador de modo escrupuloso a lo largo de toda la narración, se desarrolla ante nuestros ojos la evocación de un pasado (los encuentros infantiles en ese Palacio de Brandeso, comunes a los dos primos, encuentros que dan paso a una serie de rememoraciones familiares) y la narración de una pasión amorosa revivida por los amantes en el presente, aunque amenazada por la presencia constante de la Muerte en el cuerpo enfermizo de Concha. 
El texto que vamos a comentar precede inmediatemente, transcurre por la tarde, a la noche en que Concha muere en brazos de Bradomín. Tras esa muerte se precipita la acción en una donjuanesca escena, no exenta de inverosimilitud, y cuajada de un carácter macabro: la conquista de Isabel, el traslado del cuerpo de Concha a su habitación y el despertar de las niñas que pone fin al relato.

La situación del texto objeto de mi comentario viene a suponer, en el plano significativo, una coda-resumen de toda la Sonata de Otoño. Recoge, justo antes del desenlace, la médula semántica de la obra relevando a un primer plano el tópico central en el que convergen las isotopías semánticas de la Sonata de Otoño (sigo el sentido que a «tópico» da U. Eco 1979: 131). Ese tópico no es otro que el de la permanencia de la nobleza con sus dos atributos característicos: crueldad y piedad, o lo que es lo mismo: mundo de la hazaña guerrera y mundo ritual de la devoción. Entiendo, por lo que luego argumentaré, que este texto actúa como un microcosmos de toda la Sonata; en él se encuentran no sólo los planos temáticos de la misma sino, conjuntamente con ellos, la misma situación perspectivística o planos de la composición estructural que afectan a la posición espacio-temporal, psicológica e ideológica. La situación de estos planos de focalización en el texto es una síntesis de la misma situación en el conjunto de la Sonata.

Toda la crítica de las Sonatas viene a coincidir en que la de Otoño es la que más insiste en la evocación añorante del pasado y aquélla en que el tema de la aristocracia y el linaje se hace más relevante, precisamente por tratarse de un episodio familiar (vid. A. Zamora Vicente, $\left.1969_{2}: 34\right)$. El tono literaturizado y evasivo, voluntariamente anacrónico y arcaizante que lamentaba J. F. Montesinos para todas las Sonatas es aún más visible en la otoñal (vid. J. F. Montesinos, 1966: 301). El reencuentro con el Palacio de los Brandeso da ocasión al narrador para evocar con indisimulada añoranza los temas de la aristocracia feudal: la constante referencia a la heráldica que aparece a cada paso insistiendo en los cuatro escudos de la familia, los pliegos blasonados del papel epistolar, retratos de antepasados de rancio abolengo (cf. Valle Inclán, 1902: 7, 13, 31, 34, 35), la obsesiva insistencia en lo arcaico del linaje que da entrada a un diálogo extenso sobre los antecedentes familiares entre Bradomín, Concha y D. Juan Manuel de Montenegro (ibidem pp 50-51). Tanto es así que la única referencia de la Biblioteca del Palacio es la lectura de un libro: los Florilegios de Nuestra Señora de los que se dice autor a D. Pedro de Bendaña, obispo, miembro de la familia y fundador del Palacio (p.48). El carácter arcaico-feudal es asimismo visible en las relaciones entre los personajes. En la Sonata de Otoño sólo hay amos y criados, no existe otro paisaje que el Pazo feudal 
(vid. J. A. Maravall, 1966) y las mediaciones entre amos y criados son típico reflejo de una situación pre-burguesa, patrimonial, como se refleja en la figura del paje Florisel propiedad de la familia y admirador ingenuo de las cualidades del linaje al que sirve, sobre todo cuando aúnan, en la figura de $\mathrm{D}$. Juan Manuel de Montenegro, la estirpe a la brutalidad, gallarda indiferencia y soberbio despotismo:

«Es verdad que era magnífico aquel Don Juan Manuel Montenegro. Sin duda le pareció que no acudian a franquearle la entrada con toda la presteza requerida, porque hincando las espuelas al caballo se alejó al galope. Desde lejos, se volvió gritando:

- No puedo detenerme. Voy a Viana del Prior. Tengo que apalear a un escribano.

Florisel, que bajaba corriendo para abrir la cancela, se detuvo a mirar cuán gallardamente se partía. Después volvió a subir ła vieja escalinata revestida de yedra. Al pasar por nuestro lado, sin levantar los ojos, pronunció solemne y doctoral: 41).

—Gran señor, muy gran señor, es Don Juan Manuel! (pp.

No es indiferente a nuestro propósito subrayar cómo la figura de D. Juan Manuel Montenegro, que personifica y ejemplifica en el plano de la actualidad las cualidades de los antepasados evocadas por el narrador, es curiosamente presentada por el autor variando el foco o perspectiva para que sea el infantil paje quien subraye la gloria desde su posición de niño admirado. Igualmente veremos como en nuestro texto serán los ojos infantiles de Bradomín, en retrospectivas hacia su infancia, quienes ofrezcan la estampa legendaria de los varones de Brandeso.

La isotopia del linaje aristocrático obtenida en el deambular de Bradomin por las diferentes zonas del Palacio (jardin blasonado, biblioteca con pergaminos, salas con cuadros de antepasados, capilla etc) y aumentada notablemente por las constantes referericias a viejo, antiguo, señero, versallesco como adjetivos más comunes a cualquier objeto; esa isotopía, digo, converge con otras dos de no inferior presencia en toda la Sonata: las de la Religión y de la Muerte. La aguda retina de Amado Alonso destacó ya que la Religión y la Muerte eran las compañeras inseparables del Amor en la estructura de las Sonatas (vid. A. Alonso, $1969_{3}$ : 225). No es este el momento de recoger la enorme cantidad de textos que en la Sonata de Otoño revelan directa o indirectamente el clima ritual de la magnificencia del culto piadoso o la presencia progresivamente acentuada de la Muerte. Sí quiero atraer algo ya comentado por A. Alonso y Zamora Vicente: la isotopia religiosa es marcadamente solidaria con la del linaje hasta confundirse. La religión 
tiene presencia en cuanto tradición, con un decorativismo homólogo al del escudo nobiliario y prendido a él en la evocación feudal de Bradomín.

2.2.2. Conocidas todas estas notas contextuales hagamos breve referencia a un aspecto no señalado por la critica y que considero de capital importancia. Me refiero a la estructura composicional de la Sonata desde el plano de la focalización. Todas las evocaciones de esa nobleza mística y guerrera, salvo un diálogo entre Bradomín, Concha y D. Juan Manuel, son ofrecidas desde la óptica de un personajenarrador, Bradomín, quien al hacerlas oscila constantemente en la ordenación de su discurso entre tres planos composicionales:

A) El plano de la actualidad de la narración, presentada como Memorias de un viejo. Plano A que queda implícito como base subyacente al género de la Memoria evocadora o anterior. La Sonata de Otoño, en efecto, comienza en pasado: «...Aquella carta de la pobre Concha se me extravió hace mucho tiempo». El plano que llamo $A$ es el del discurso presente respecto al cual tiene sentido ese pasado verbal. Este plano composicional informa de muchos detalles de tonalidad: añoranza, lejania, sentimiento de culpa etc., que se encuentran presentes en la fraseologia de toda la Sonata y que ahora nos es imposible analizar. Hay referencias concretas a este plano, sobre todo adverbiales del tipo "yo aún recuerdo", etc.

B) El plano de la Historia actual, de lo narrado, objeto de las Memorias: los tres días de convivencia de Concha y Bradomín en el palacio de Brandeso. Suponen respecto de A una retrospectiva homodiegética, cuya analepsis tiene un alcance de varios años (la distancia exacta entre $\mathrm{A}$ y $\mathrm{B}$ nos es desconocida) y una duración de tres días (traduzco terminología de G. Genette, 1972). Este plano composicional ocupa la mayor parte de la Sonata. Es el plano de la Historia-Objeto.

C) Un tercer plano composicional lo forman, a lo largo de toda la Sonata, las retrospectivas originadas en $B$ en que el narrador y otros focalizadores (entre ellos Concha, D. Juan Manuel, etc) rememoran ya el pasado infantil $\left(C_{1}\right)$, ya los antecedentes familiares anteriores $\left(C_{2}\right)$. El alcance o inclinación de estas retrospectivas es diverso («unos años» en cuanto al pasado infantil y uhasta varios siglos» en la rememoración de los antepasados familiares). La perspectiva es solamente homodiegética e interna en el primer caso $\left(C_{1}\right)$ y netamente exterior en el segundo caso, frecuentemente a través de los objetos del Palacio.

Podrá observarse que la estructura composicional aquí dibujada es en el nivel fraseológico al mismo tiempo aspectual, espacio-temporal, psicológica (interior vs. exterior) e ideológica (posición de añoranza como actitudes de los focalizadores). Como dije arriba la composición textual del nivel fraseológico unifica una convergencia en que es inse- 

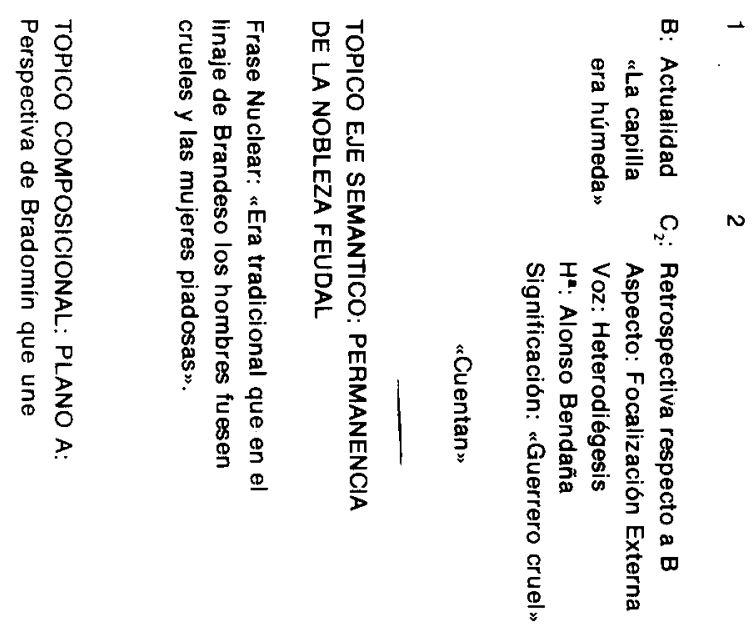

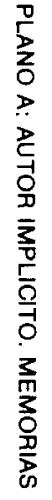
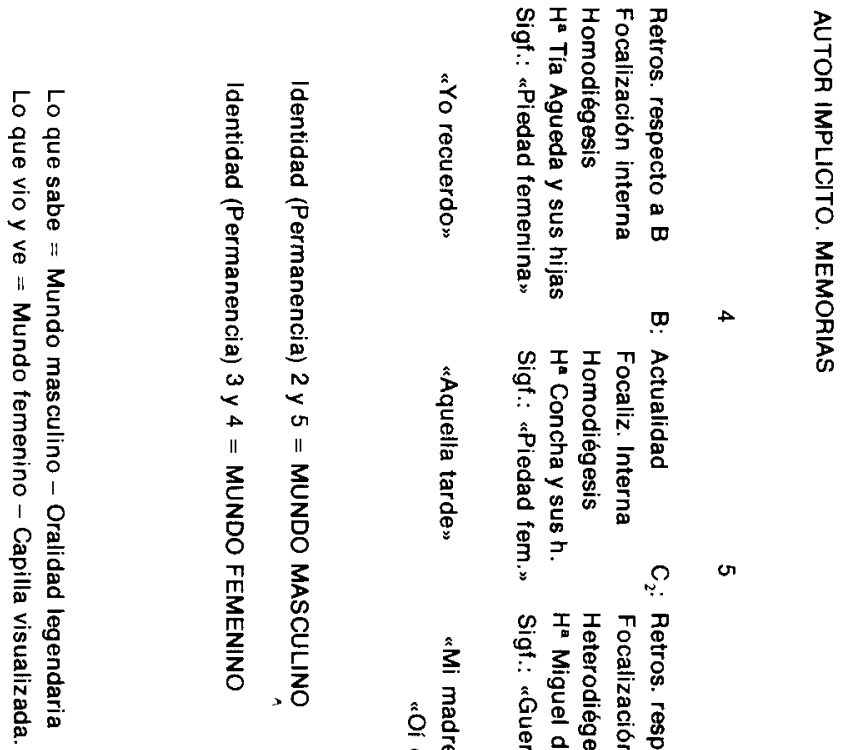

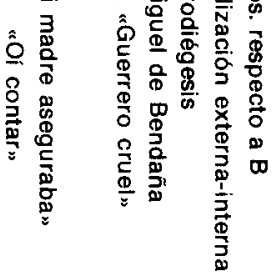


parable la perspectiva el tiempo, el espacio, la interioridad y la actitud ideológica del focalizador.

2.3. Una vez dibujado el contexto temático y composicional en que se sitúa el texto objeto de mi análisis, hora es ya de abordarlo. Insisto en que el mismo supone una sintesis del conjunto de la Sonata, tanto en las isotopías semánticas que acabo de recordar como en los planos composicionales. Por ello podré defenderlo como un microcosmos del conjunto de la obra. En el cuadro adjunto he querido reflejar la doble estructura composicional y temática del texto que describe la capilla de los Brandeso:

2.3.1. En el cuadro han quedado reflejados los cambios de focalización que presenta el texto. Los números $(1,2,3,4,5)$ que sitúo en el arranque de cada cambio reflejan estos en su sucesión sintagmática en el texto. Las letras mayúsculas $\left(B, C_{1}\right.$ y $\left.C_{2}\right)$ están referidas a los planos composicionales - perspectivisticos que acabo de distinguir en 2.2.2 para el conjunto de la Sonata: B se refiere a la Historia- Objeto del encuentro Bradomín y Concha tal como la rememora Bradomín desde A (plano A que sólo aparece en el texto de modo explícito en el adverbio «aún recuerdo" y que está presente, como actividad de escribir unas Memorias, de modo implícito, en todo el texto). Pertenecen a B los fragmentos que comienzan «La capilla era..." y "Concha quiso aquella tarde...», esto es el plano de actualidad de lo narrado, plano con el que comienza el texto y del que arrancan todas las retrospectivas. El plano $C$ se refiere como dije al plano perspectivístico o composicional de las retrospectivas respecto de $B$. Al igual que ocurre en toda la Sonata de Otoño hay en este texto dos tipos de retrospectivas:

$\mathrm{C}_{1}$ : número tres del cuadro. Retrospectiva de rememoración de un pasado infantil vivido por Bradomin y por tanto en plano focalizador de tipo interno (en cuanto al plano psicológico de Uspenki) y homodiegético ( $Y_{O}$ aún recuerdo»).

$\mathrm{C}_{2}$ : números 2 y 5 del cuadro. Retrospectivas de rememoración de antecedentes familiares en focalización externa y heterodiegética («Cuentan...» «Mi madre aseguraba...»«Oí contar...»).

2.3.2. Se podrá observar que la estructura textual del fragmento que venimos comentando está organizada desde estos planos composicionales que denomino focalización y que permiten dibujar una red de coincidencias estilísticamente muy pertinentes. En efecto si se leen las lí- 
neas de cada columna o entrada del cuadro se ve cómo coinciden y convergen en cada plano no sólo los elementos de orjanización del discurso (aspecto o foco, voz, temporalidad) sino también los objetos narrados: la historia recogida en cada plano (familia femenina o masculina de Bradomín) y su significación isotópica respecto a las líneas temáticas centrales de la Sonata de Otoño (legendaria aristocracia feudal de guerreros crueles y piedad ritual femenina). Lo importante para la composición textual es la convergencia de los planos semánticoideológicos con los fraseológico-discursivos, convergencia que se reitera en todos los planos del fragmento y que confirma, creo, mi hipótesis de ser el fraseológico-discursivo no un nivel o plano del análisis sino la unidad de coincidencia objetual o textual de todos los otros.

2.3.3. Por último este cuadro habrá, espero, subrayado con la evidencia gráfica mi hipótesis de ser este fragmento un microcosmos donde se recogen:

a) las líneas temáticas centrales de la Sonata de Otoño. Tales lineas (religiosodad y legendaria prosapia feudal) omnipresentes en toda la Sonata no son como puede verse sino dos caras de una misma moneda, una cara es la femenina y otra la masculina, de la nobleza feudal. Por ello he considerado la frase «Era tradicional que en el linaje de Brandeso los hombres fuesen crueles y las mujeres piadosas" como la frase nuclear o tópico semántico generador de todo el texto.

b) Pero más interesante es que este fragmento recoja no sólo ese doble tema de religiosidad y legendaria crueldad sino también todos los planos perspectivísticos o composicionales de la Sonata. Esta coincidencia permite leer el pasaje como desarrollo del tema Permanencia de la nobleza, puesto que lo fundamental en el nivel semántico no es tanto que la nobleza feudal sea así ahora sino que fue así en un dia lejano (siglo XV: Alonso Bendaña, Beatriz de Montenegro), continuaba asi en días no tan lejanos (tía Aqueda y el abuelo de Concha: Miguel de Bendaña) y continúa asi ahora mismo (Concha y sus hijas y D. Juan Manuel, este último no presente en el fragmento pero sí en la Sonata como figura de pervivencia de los hábitos feudales masculinos). La mejor manera de mostrar Valle Inclán esa continuidad o permanencia es la reiteración de actitudes del mundo masculino y femenino, pero, para mejor mostrarla aún, se establece a partir de un mismo personaje, Bradomin, que, bien sea en la esfera del recuerdo, bien en la de la visión actual, unifica el antes y ahora de la nobleza. Bradomín une en sus Memorias lo que sabe por que se lo contaron otros o lo vio de niño (el antes) y lo que ve (el ahora). 


\section{Desarrollo analítico del cuadro.}

Una vez analizada la estructura global del fragmento, su composición perspectivistica y su significación en el conjunto semántico de la Sonata de Otoño, analizaré con mayor pormenor las cinco secuencias discursivas que he distinguido en el cuadro.

3.1. El fragmento comienza con la descripción de un espacio generador de todas las evocaciones: la capilla. La focalización elegida es aparentemente externa, mas sólo aparentemente puesto que la visión incluye inmediatamente a través de esa triple adjetivación tan grata al Valle Inclán modernista (cf. A. Alonso, 1969: 247-248, quien analiza la importancia de la trimembración en la frase de las Sonatas) una nota de percepción subjetiva por tres sensaciones: "La capilla era húmeda (sensación táctil), tenebrosa (s. visual), resonante (s. sonora)" (Para la importancia de las sensaciones en las Sonatas vid. A. Zamora, 19692; 136-164).

En esta interiorización o focalización interna referida al Emisor colabora también la temporalidad. Tal como destaca Uspenki, el plano fraseológico y el temporal están íntimamente relacionados. En efecto, la temporalidad elegida es la del pretérito imperfecto: "La capilla era... Sobre el retablo campeaba... Era el escudo". La aspectualidad imperfectiva resitúa el tiempo verbal pasado, habitual en las visiones externas, otorgándole una dimensión explícita de actualidad referida al momento de la percepción. Como se sabe el pretérito imperfecto goza de un status particular puesto que en él convergen pasado temporal y aspectualidad durativa. El tiempo de la historia es pasado pero por su aspecto imperfecto se actualiza en el momento del discurso leído.

La elección de esta temporalidad no es fortuita. La veo como generadora de toda la estructura textual de la estampa o fragmento. En efecto, en este fragmento un personaje hará la evocación de un linaje. Para el linaje el tiempo adecuado es el pasado por ser el tiempo de la historia, como destacó E. Benveniste (cf. E. Benveniste, 1966). Sin embargo interesa no sólo el linaje sino su evocación por medio de la perspectiva de Bradomín. De ahí el imperfecto que vincula fraseológicamente los dos planos textuales: un pasado (el de la historia) y un presente (el arranque de la evocación del personaje que actualiza para el lector una simultaneidad durativa.)

3.2. La secuencia 2 del texto se inicia con "Cuentan...» y supone una retrospectiva de lejano alcance y focalización externa con voz heterodiegética $\left(C_{2}\right)$. 
Es muy visible el cambio de foco y de historia. Pero ese cambio respeta sin embargo un elemento esencial: la estructura verbal de "Cuentan..." continúa el proceso fraseológico abierto con «Era...». "Cuentan..." es presente, pero es un verbum dicendi que en este contexto implica pasado. Cuentan, como verbum dicendi actualiza la simultaneidad proyectada del presente con la referencia explícita al pasado (se cuentan historias pasadas), por lo que comparte la estructura funcional que habiamos visto en el imperfecto «Era...» El verbo «Cuentan....» introduce una pequeña historia: la de Alonso de Bendaña narrada con focalización externa y plural («Cuentan») y tiempos pasados (vistió, soltó, murió).

La focalización externa de «Cuentan» se concreta un poco más adelante en la perspectiva de Candelaria, la niñera de Concha, vehículo de transmisión de la leyenda. La perspectiva continúa siendo externa, pero mediante ese personaje se liga con la persona del narrador Bradomín de ahí que la focalización externa coincida sin embargo con una homodiégesis respecto a la voz («solía en otro tiempo referirnos). El sintagma "en otro tiempo" es redundante respecto a la marca o sema temporal incluido en el verbo "solía" y tiene la exclusiva función de hacer notar - como evocación que es- la actividad actual del discurso (presupuesto «en este tiempo»).

El último verbo de esta parte, Candelaria sabia, está en concomitancia con todo lo dicho: imperfecto + pasado, que incluye el sema de $\mathrm{I+}$ continuidad] relativo a la pervivencia de la leyenda como verdad ancestral. Quizá desde el punto de vista de la focalización quepa leer aquí una focalización distanciada o irónica del narrador al establecerse el contraste entre lo increible de la leyenda y el sema de [+ certeza] que incluye el verbo sabia [+ certeza] que dos enanos negros se habian llevado al infierno... [- realidad].

Una vez finalizada esta evocación $\mathrm{C}_{2}$, el narrador introduce la frase nuclear que actúa como tópico generador de todo el texto: « Era tradicional que en el linaje de Brandeso los hombres fuesen crueles y las mujeres piadosas!». El tono admirativo confirma la perspectiva de distanciamiento, ya marcada en «sabia», respecto a las creencias supersticiosas. Aparte de comportarse como un anuncio de lo que sigue, esta frase condensa todo lo que llevamos dicho sobre esta parte del texto, pues si la analizamos encontramos en ella tanto los tópicos temáticos como lo medular de la estructura discursiva del co-texto previo:

- Respecto a la estructura discursiva la frase «Era tradicional...» recoge la aspectualidad no finita, el tiempo pasado y la visión externa presentes en «tienen una leyenda», "cuentan", sabía historias», "solía referirnos», «sabia». Tanto esa focalización como esa temporalidad y 
aspectualidad verbal (era, sabía, solía) es la más apropiada a la esfera de la leyenda.

- Respecto a los tópicos temáticos vemos en esta frase «Era tradicional...» dos temas claves: tradicionalismo y linaje. Ambos son isotópicos entre sí e isotópicos respecto a un haz que cruza toda esta parte del texto en convergencia de los semas referidos a continuidad histórica, estirpe noble etc. Los lexemas y sintagmas que formarian esa isotopía recogida en tradicional y linaje son los siguientes en esta parte del texto: capilla (funeraria), escudo, ejecutorias, fundador, Mayorazgo, Nobiliarios, leyenda, criados antiguos, historias, genealogias, casa de sus señores, viejos nobiliarios, que ya nadie lee ( = añejos, vetustos). En esta isotopía habría que incluir también las veces que aparece Capitán, sobre todo por estar con grafema de mayúscula o principal, que redunda en el sema de estirpe nobiliaria en el que coinciden todos los lexemas y/o sintagmas enumerados.

Vengo insistiendo, por último, en la necesidad de incluir en la composición textual de este tópico los verba dicendi por los que el narrador ha sugerido en este texto que su focalización es directamente dependiente de la esfera del recuerdo + esfera de la oralidad (ambas notas son inherentes al tópico textual de la Leyenda). Tales verba dicendi son: “cuentan», «solía referirnos», «la refieren».

3.3. La secuencia número 3 de mi cuadro introduce una retrospectiva cercana y homodigética, del tipo $\mathrm{C}_{1}$ por tanto. Se inicia con "Yo aún recuerdo» lo que no deja lugar a dudas respecto al cambio de registro focalizador y al alcance de la analepsis o retrospectiva. Creo interesante subrayar, sin embargo, que yo aún recuerdo continúa manteniendo en su estructura verbal discursiva la simultaneidad de dos tiempos: el pasado sugerido por «recuerdo» y el presente de la temporalidad verbal, destacado además por el adverbio aún referido al plano A (memorias) o actualidad de la narración. Los verbos siguientes pasan inmediatamente a la forma del pretérito imperfecto que, como ya comentamos en "La capilla era...", mantenían una dualidad pasado + proyección durativa sobre el presente de la evocación: “mi tía Agueda oía misa» «tribuna estaba», "coronaban», «gozaba el privilegio», «estaba enterrado", "tenía la estatua" (bis), "alumbraba», "parecían ofrecerse», «era aquel» «brillaba», «tenía tímido aleteo».

En esta secuencia ofrece interés el visible carácter dual y simétrico de la escena y espacio visualizado, que por otra parte es un desarrollo o proyección de la frase que hemos llamado nuclear y que definia el linaje de Brandeso: mundo masculino guerrero y mundo femenino piadoso 
1. Derecha del altar

2. estaba enterrado

3. Capitán Alonso Bendaña

4. con otros caballeros de su linaje

5. El sepulcro tenía la estatua orante

de un guerrero
1'. A la izquierda

2'. estaba enterrada

3'. Doña Beatriz Montenegro

4'. con otras damas de abolengo

5'. El sepulcro tenía la est. orante

de una religiosa

Linaje Brandeso $=$ Hombres crueles y mujeres piadosas.

3.4. Tras esta segunda retrospectiva la secuencia 4 del relato vuelve al tiempo de actualidad (tipo B) con que había comenzado en "La capilla era húmeda...» (secuencia 1). La visualización de la escena de Concha y sus hijas se marca temporalmente con «Aquella tarde» que indica la simultaneidad de tiempo de la historia y esfera de la evocación con que comenzó el texto. La simetría con la secuencia anterior referida a tía Agueda es evidente:

secuencia 3: “Mi tía Agueda oía misa acompañada de todas sus hijas» secuencia 4: "Concha se arrodilló ante el altar acompañada de las niñas.»

Esta simetría constata la "añeja e hidalga costumbre» y por tanto la continuidad o permanencia en sus hábitos de vida de la esfera femenina de la nobleza feudal.

La escena visualizada "aquella tarde" (secuencia 4) ofrece una interesante dualidad desde el punto de vista de la focalización. Los tiempos verbales de la historia (lo que en la escena visualizada ocurre) se encuentran en pasado perfectivo: "se levantó», "cruzó el presbiterio", «llamó a sus hijas». En tanto que para la visualización como tal, para la mirada, sigue manteniendo la estructura que venimos viendo a lo largo de todo el texto para la perspectiva del narrador: el pretérito imperfecto, mediante un verbum sentiendi que establece las condiciones de la percepción: "Yo solamente oía...", "oia todas las palabras".

3.5. La escena se vuelve a interrumpir para introducir la que he numerado secuencia 5 , una retrospectiva respecto a $\mathrm{B}$, con focalización variable (externa e interna) y heterodiégesis $\left(C_{2}\right.$, por tanto). Tal interrupción tiene por objeto la evocación de un nuevo personaje: Mi- 
guel Bendaña. Como viene ocurriendo a lo largo del texto se establece inmediatamente el alcance de la analepsis y punto de referencia a la "distancia» respecto del narrador: "era el abuelo de Concha». Inmediatamente se anotan las condiciones de información del narrador (como había ocurrido en la secuencia 2 con Alonso Bendaña en "cuentan" y "Candelaria... solía referirnos"): su madre le llevó a Palacio. Creo interesante anotar unos cambios de registro focalizador en esta secuencia que no son ajenos, pienso, a la estructura textual que vengo glosando. La heterodiégesis y perspectiva externa de la secuencia 2 (la referida a Alonso Bendaña) se mantiene aquí en cuanto a la voz heterodiégetica pero cambia el punto de vista, que ahora es interno: es el narrador quien asistirá a una cierta distancia (se trata de un niño) a los hechos de la muerte de Miguel de Bendaña. Sin embargo, y este es un hecho muy significativo, los antecedentes de Miguel de Bendaña, su historia pasada, son narrados de nuevo (como en Alonso Bendaña) con perspectiva externa y mención explícita a la transmisión oral-legendaria: "Una noche, poco después de su muerte oi contar en voz baja...». Luego la simetría en la focalización de las secuencias 2 (Alonso Bendaña) y 5 (Miguel Bendaña) es muy grande; a la vez son simétricas las actitudes de guerrero déspota, cruel y hereje condenado que se predican igual para el antepasado del XV y para el abuelo de Concha. Se trata, pues de la permanencia de los hábitos del linaje masculino de los Brandeso (paralela a la permanencia del femenino en sus hábitos de piedad). Volviendo al mundo masculino es idéntica incluso la estructura fraseológico-tonal que cierra las dos retrospectivas de los Bendaña (secuencias 2 y 5): una exclamación del narrador. ¿Cabe hallar significación alguna a estas exclamaciones?, ¿Cuál es la posición ideológica del narrador?

\section{Focalización e ideología}

4.1. B. Uspenki ha insistido en la importancia que la fraseología puede tener como relevancia del plano ideológico de la focalización ( $\mathrm{B}$. Uspenki, 1973: 8 y ss.). Es este el momento de referirnos a ese plano ideológico en el texto que analizamos. Uspenki habla de cómo un punto de vista no es solamente una situación espacial, temporal o psicológica sino también una actitud del narrador hacia lo que narra en que traduce éste su ideología o concepción del mundo. Uspenki, que sigue a Bajtin muy de cerca en este punto, se refiere sobre todo a la perspectiva ideológica en la relación autor-personaje y se pregunta primeramente quién dentro de la obra novelesca representa o es vehiculo de la ideología del autor. Tiene asimismo en cuenta la pluralidad 
de perspectivas ideológicas o lo que Bajtin habia llamado polifonia y dialogismo. Por último Uspenki admite que el plano ideológico del punto de vista es el menos accesible al estudio formal (B. Uspenki, 1973: 13). Estamos sin embargo de acuerdo con Fowler (1982: 216) en que Uspenki, aunque dice que la visión del mundo de un personaje o la del autor mismo puede ser definida en el análisis estilistico de su habla (B. Uspenki, 1973: 15), es demasiado poco lo que ofrece sobre esta cuestión. El mismo R. Fowler, aunando en el estudio citado perspectivas de la estilistica spitzeriana (por fin rescatada de la primitiva incomprensión que le propinó el mundo anglonorteamericano) y de la escuela de Halliday (vid. Bibliografia), puede proponer pautas de análisis de la perspectiva ideológica del narrador a través del análisis de determinados rasgos lingüisticos que pueden mostrarse sintomáticos y que, como Halliday, Fowler, Kress y otros (vid. Bibliografía) han mostrado formar parte del sistema lingüistico mismo, traductor fiel del punto de vista ideológico. R. Fowler analiza certeramente algunos pasajes del Titus Groan de M. Peake. Los elementos de la estructura lingüistica traductores del punto de vista ideológico recorridos por Fowler son, entre otros, los auxiliares modales, los adjetivos de evaluación, adverbios modales, verbos de evaluación (creer, aprobar, tener por cierto etc.) y frases hechas.

4.2. No es este el momento de analizar la totalidad de la focalización ideológica del narrador en este texto (que no podría hacerse sino en el conjunto de la Sonata) pero sí de tener en cuenta algunos de los elementos más importantes de ese tipo de focalización distinguido por Uspénki en su interrelación con el nivel fraseológico. En primer lugar es preciso recordar como punto de partida que la actitud del narrador no es otra que la del Marqués de Bradomín y no la de Valle Inclán. Esta constatación parece obvia en la medida en que la relación del narrador con los hechos narrados está explicitamente marcada en el texto: "Candelaria solía referirnos", «mi tía Agueda», «mi madre» etc. Dado que no se puede sostener que Candelaria personaje contase a Valle Inclán o que la tía de D. Ramón se llamase Agueda o sus antepasados Bendaña, habrá que coincidir en que la posición evaluativa del mundo narrado corresponde al personaje y no al autor. En otro lugar he ponderado la importancia y utilidad que en el análisis narrativo tiene la distinción de los pactos narrativos (vid. J. M. Pozuelo, 1978) y no es cosa de insistir en la cuestión, por más que con ello saldemos de un plumazo la controvertida cuestión del reflejo de la ideología del autor, noble y carlista y su identificación con Bradomín, aspectos muy certeramente tratados por la crítica, pero en los que conviene medir las 
distancias y prevenirse de los mecánicos reflejos entre autor y mundo creado. Pero volvamos al narrador. ¿Cuál es la distancia y evaluación ideológica del narrador respecto a los hechos?, ¿Cómo se traduce esa distancia? (para «distancia» sigo a W. Booth, 1974.)

Aunque aparentemente el narrador no intervenga en la evaluación de lo narrado y se sitúe en una posición de espectador-auditor, creo percibir en su habla una valoración admirativa del mundo de la leyenda o mundo masculino. Es más evidente en la presentación de Miguel de Bendaña (secuencia 5). Los adjetivos evaluativos son muy claros: déspota y hospitalario, aparentemente negativo el uno y positivo el otro, para añadir que ambas cualidades lo son por fiel respeto a la tradición hidalga y campesina de todo su linaje. Esta nueva adjetivación explica la anterior en correspondencia acoplada: déspota por hidalgohospitalario por campesino, y sobre todo anula el carácter negativo de la primera caracterización. Los atributos siguientes, «Enhiesto como un lanzón», «alejado de los plebeyos» distan de ser peyorativos. No en vano dan lugar a una de las pocas intromisiones del narrador quien, en discurso directo y en una estructura fraseológica de admiración ponderativa concluye: “iHermosa y noble locura!» (el subrayado siempre es mio). Más aún que los adjetivos, que no ofrecen lugar a dudas, me importa destacar la proximidad ideológica que revela la necesidad de introducirse el narrador en la evaluación de su héroe mediante una frase exclamativa en discurso directo. Las siguientes caracterizaciones: «aún tenia el alma soberbia, gallarda y bien templada» y su comparación con la esfera de la lucha en lanzón y gavilanes revelan siempre el contenido de «bravura».

Dado nuestro interés por las focalizaciones como vía de composición múltiple no está de más que anotemos un cambio de registro muy significativo: lo realmente punible, «matar a un criado suyo», mueve un cambio de foco desde la focalización interna del narrador a la de la esfera del cuento o leyenda: «una noche oí contar en voz baja..." El paralelismo con la figura de Alonso Bendaña de la secuencia 2 vuelve a ser claro, pero en ambos casos, he aquí lo importante, el narrador se distancia de los hechos atroces, focalizándolos desde la esfera de lo legendario, zafándose de toda responsabilidad respecto a la verdad real de los hechos. Incluso para la evaluación de la herejía de Miguel Bendaña el narrador, que no ha tenido empacho en ofrecer directamente la evaluación de su bravura e hidalguía, desplaza para la herejía el punto de vista hacia un foco de evaluación diferente, perteneciente al mundo femenino: “Mi madre aseguraba que no habia visto nada semejante...»

La perspectiva ideológica o evaluación del narrador respecto al mundo femenino, caracterizado desde la frase nuclear como «pia- 
doso", muestra, creo una distancia mayor y se resuelve en una caracterización reductora del mundo femenino a la esfera peyorativa de un ritual tradicional que se cumple sin demasiado sentimiento o sinceridad. El narrador no interviene nunca para evaluarlo, pero creo posible, según lo marcado por Uspenki y Fowler, percibir su actitud en rasgos de su discurso y en la atmósfera mortecina que lo rodea. La misa de tía Agueda está presentada con la motivación de la costumbre: "Siguiendo añeja e hidalga costumbre» y a la hora de relatar en la secuencia siguiente la oración de Concha hay un adjetivo sintomático: "guiaba moribunda las avemarias", adjetivo que no seria tan significativo, si no estuviera apoyada su evaluación negativa por la insistencia del narrador en una percepción doble: ritualizada y en murmullo que apenas se oye en la oración de Concha y perceptible y clara, sin embargo en la respuesta de las niñas, menos aquejadas de esa automatización del rito que el narrador ha dibujado en la escena de la oración.

Baste con los datos apuntados para mostrar la enorme importancia que en la composición artística puede tener la interrelación del plano ideológico y el fraseológico de la focalización.

4.3. Por último voy a referirme a un aspecto de la composición textual de este capítulo que no pasa desapercibido a ningún lector: la insistencia del narrador en las condiciones de enfoque, sobre todo visuales, de su focalización. He apuntado más arriba la importancia de la focalización interna por la que un personaje noble, Bradomín, reúne en su recuerdo del pasado y en su percepción presente la imagen de continuidad de unos modos de vida. En esa continuidad permanece no sólo el narrador, sino también un idéntico espacio y toda una escenografia. Dentro de ésta ocupa un lugar preeminente la lámpara del presbiterio que suministra una luz tenue y facilita la atmósfera tenebrosa, de tímido aleteo de sombras y luces. La iluminación es interior como el foco narrativo y el narrador pone cuidado en describir los objetos sujeto a ese foco de luz interno de la lámpara dèl presbiterio que se encuentra presente en la secuencia 3 (tía Agueda) y en la 4 (Concha).

La composición de la perspectiva temporal de la escena de Concha está fuertemente cohesionada por una doble evolución: la de las condiciones de luz en que la escena está descrita y la evolución del estado de consciencia o lucidez de la mirada del narrador-personaje. En efecto, el narrador marca con el sintagma «Aquella tarde», el momento en que Concha se arrodilla ante el altar y al comienzo del último párrafo del texto encontramos una marca de duración de la escena: «la tarde agonizaba" y poco después: "yo entonces veía el cielo ya oscuro, la faz de la luna pálida y sobrenatural..." Vuelve luego a insistirse en el 
débil resplandor de la luz de la lámpara que temblaba (en simetría con el tímido aleteo de la lámpara en la escena del recuerdo de tía Agueda). Todas estas indicaciones de las condiciones de luz, a la vez que sirven para mostrar la duración de la escena, están relacionadas como dije con el estado de consciencia, progresivamente nebulosa de la perspectiva del narrador:

"Yo me adormecía en la tribuna..."

"Yo solo distingui una sombra que rezaba"

"Vi pasar sus sombras y columbré que se arrodillaban..." "Las niñas escuchaban y adiviné sus cabelleras sueltas»

No es difícil percibir una gradación que progresivamente avanza, como la tarde declina, hacia la disolución de la perspectiva del narrador que es cada vez más etérea, misteriosa y sugerente respecto al ambiente de intemporalidad casi fantasmal en que se resuelve esta percepción y que introduce la presencia de la muerte, esa otra gran isotopía de la Sonata. No sería aventurado extraer una consecuencia ideológica de esta ordenación. En el mundo de las Sonatas se retrata una nobleza decadente, un ser sin ser, que vive de las remembranzas del pasado. De una nobleza hidalga queda el ademán, lo externo e incluso lo más reductor: el culto de sus miembros a su propia tradición. Quizá no escape a esta lectura el hecho de que las hazañas de los Bendaña se presenten en la esfera lejana del recuerdo, de la leyenda que fue y ya no es. En cambio el tiempo presente, el de Concha, es sólo el ritual de un culto a ese pasado, resuelto finalmente en una mirada adormecida y lánguida, mortecina, esteticista y decadente, bellamente anacrónica.

\section{Bibliografía citada}

Alonso, Amado $\left(1969^{3}\right)$, Materia y forma en poesía, Madrid, Gredos. Bal, M. (1977), La Narratologie, París, Kliencksieck.

Bajtin, M. (1970), La poetique de Dostoievsky, París, Seuil (Original de 1963).

Baquero Goyanes, M. (1963), Perspectivismo y contraste. De Cadalso a Pérez de Ayala, Madrid, Gredos.

- (1970), Estructuras de la novela actual, Barcelona, Planeta.

Benveniste, E. (1966), Problemes du linguistique generale. Cito por la edición castellana de México, Siglo XXI, 1971.

Booth, W. (1974), La retórica de la ficción, Barcelona, Bosch. (Original de 1961.) 
Eco, U. (1979), Lector in fabula. Cito por la edición castellana en BarceIona, Lumen, 1981.

Fowler, R. (1982), "How to see through language: perspective in fiction", en: Poetics, 11, 3, pp. 213-235.

Friedmann, N. (1967), «Point of view in fiction: The development of a critical concept», en P. Stevick (ed.), The theory of the novel, New York, The Free Press, pp. 108-138.

Garcia Berrio, A. (1973), Significado actual del formalismo ruso, BarceIona, Planeta.

- (1984), «Epilogo. Más allá de los «ismos»: sobre la imprescindible globalidad crítica», en P. Aullón de Haro (ed.), Introducción a la critica literaria actual, Madrid, Playor.

Genette, G. (1972), Figures III, París, Seuil.

Halliday, M. A. (1971), "Linguistic function and literary style: an inquiry into language of W. Golding's The Inheritors", en: S. Chatman (ed.), Literary Style: A Simposium, Oxford University Press.

Kress, G. R., and Hodge, R. (1979), Language as ideology, London, Routledge and Kegan Paul.

Mainer, J. C. (ed.) (1981), Modernismo y 98, Barcelona, Crítica. (F. Rico, Historia y critica de la Literatura Española, vol. 9.)

Maravall, J. A. (1966), "La imagen de la sociedad arcaica en Valle Inclán», en Revista de Occidente, $n^{\circ}$ 44-45, pp. 240-249.

Montesinos, J. F. (1966), «Modernismo y esperpentismo o las dos evasiones", en Revista de Occidente, $n^{\circ} 44-45, p p .152-160$. Cito por J. C. Mainer (ed.) (1981).

Pozuelo Yvancos, J. M. (1978), «El pacto narrativo: Semiología del receptor inmanente en el Coloquio de los Perros», en: Anales Cervantinos, $\mathrm{n}^{\circ}$ XXVII, Madrid, C.S.I.C., pp. 147-176.

- (1983), La lengua literaria, Málaga, Ágora.

Scholes, R., and Kellogg, R. (1966), The Nature of Narrative, New York, Oxford Univ. Press.

Todorov, T. (1969), Poétique, París, Seuil.

Uspenki, B. (1973), A poetics of composition. The estructure of the artistic text and typology of a compositional form, Berkeley, Univ. of California Press.

Valle Inclán, R. (1902), Sonata de Otoño. Cito por la 6. ${ }^{a}$ edición de Espasa Calpe, Madrid.

Volosinov, V. (1976), El signo ideológico y la filosofia del lenguaje, Buenos Aires, Nueva Visión. (La edición original rusa es de 1929.) Zamora Vicente, A. $\left(1969^{2}\right)$, Las Sonatas de Valle Inclán, Madrid, Gredos. 